Unless otherwise noted, the publisher, which is the American Speech-LanguageHearing Association (ASHA), holds the copyright on all materials published in Perspectives on Fluency and Fluency Disorders, both as a compilation and as individual articles. Please see Rights and Permissions for terms and conditions of use of Perspectives content: http://journals.asha.org/perspectives/terms.dtl

\title{
The Impact of a Stuttering Disorder on Western Australian Children and Adolescents
}

\author{
Janet M. Beilby \\ School of Psychology and Speech Pathology, Curtin Health Innovation Research Institute, \\ Curtin University, \\ Perth, Western Australia, Australia \\ Disclosure: Janet M. Beilby has no financial or nonfinancial relationships related to the content \\ of this article.

\section{Michelle L. Byrnes} \\ Australian Neuro-Muscular Research Institute, CNND, University of Western Australia \\ Crawley, Western Australia, Australia. \\ Disclosure: Michelle L. Byrnes has no financial or nonfinancial relationships related to the \\ content of this article.

\section{J. Scott Yaruss} \\ Department of Communication Science and Disorders, University of Pittsburgh \\ Pittsburgh, Pennsylvania \\ Disclosure: J Scott Yaruss is the co-author of the OASES and receives royalties from its sale.
}

\section{Abstract}

In this study, we examined the impact of a stuttering disorder on children $(n=50)$ and adolescents $(n=45)$ living in Western Australia. We compared the reactions and experiences of children and adolescents who stutter to children and adolescents who do not stutter. We compared the participants who stuttered and the fluent participants using adapted versions of the Overall Assessment of the Speaker's Experience of Stuttering (OASES). We also examined the relationship between biopsychosocial impact and stuttered speech frequency. We saw higher levels of adverse impact in young people who stuttered compared to their fluent peers. In addition, we found moderate correlations between OASES scores and stuttered speech frequency in children. These findings provided a baseline for establishing the degree of negative impact that a stuttering disorder may bring about in children and adolescents. The experiences of young people who stuttered were significantly different from the experiences of young people who were typically fluent. These findings reinforce the notion that stuttering is a disorder that can lead to negative impact for young people.

\section{Biopsychosocial Model of Stuttering}

Researchers and clinicians working in the field of stuttering disorders have argued for a conceptualization of stuttering that delineates both the surface behaviors present in an individual's speech and the psychosocial impact or consequences that stuttering has on his or her life (Cooper \& Cooper, 1996; Gabel, 2006; Quesal, 1989; Rustin, Cook, \& Spence, 1995; Yaruss \& Quesal, 2004, 2006). For instance, Yaruss and Quesal (2004) adapted the 
International Classification of Functioning, Disability and Health (ICF), presented by the World Health Organization (WHO, 2001) to describe the multidimensional nature of stuttering. They stated that they selected that framework because it considers factors beyond the observable characteristics of the stuttering impairment. Specifically, these added factors can be viewed in terms of an integrated holistic biopsychosocial model that contains several interacting components: biological factors, which consist of the presumed aetiology or underlying causes of the disorder, as well as the impairment in body function evident in the observable characteristics of stuttering; psychological factors, which include the speaker's affective, behavioral, and cognitive reactions to stuttering; social factors, which include the effects of the environment on stuttering, such as the reactions of others, and which may be indicated by the difficulty the speaker may have in different speaking situations; and the overall impact of stuttering on the speaker's life, as indicated by the limitations in communication activities and restrictions in participation in daily life.

The study of the biopsychosocial effects of the stuttering disorder on children and adolescents who stutter is particularly important, because research to date has not fully delineated the nature or extent of the negative impact that stuttered speech may have for these age groups. Many adults who stutter experience a variety of affective or emotional reactions to their stuttering. Examples include feelings of embarrassment, anxiety, fear, shame, guilt, anger, isolation, loneliness, inadequacy, and other negative emotions accompanying stuttered speech (e.g., Cooper, 1993; DeNil \& Brutten, 1991; Guitar, 2006; Logan \& Yaruss, 1999; Manning, 2010; Shapiro, 2011; Sheehan, 1970; Vanryckeghem \& Brutten, 1996, 1997; Watson, 1988; Yaruss, 1998; Yaruss \& Quesal, 2004, 2006). In addition, cognitive reactions such as low self-esteem, diminished self-confidence, and reduced feelings of self-efficacy also are common (Blood \& Blood, 2004; Healey \& Scott, 1995; Manning, 2010; Ornstein \& Manning, 2002; Ramig \& Bennett, 1995; 1997; Ramig \& Dodge, 2005; Reeves \& Yaruss, 2012; Starkweather \& Givens-Ackerman, 1997; Vanryckeghem, Brutten, \& Hernandez, 2005; Yaruss, 1998; Yaruss \& Quesal, 2004, 2006).

From a developmental perspective, researchers have not yet clarified when these reactions emerge in young people. It has long been known that negative attitudes can develop when children are relatively young (Bloodstein, 1960), and more recent research has highlighted the importance of considering negative reactions even in very young children who stutter (Ezrati-Vinacour, Platzky, \& Yairi, 2001; Vanryckeghem et al., 2005). Nevertheless, researchers have not yet fully explored the way in which these negative reactions and experiences affect school-age children and teenagers.

Researchers have found that stuttering has a significant influence on a speaker's overall quality of life (Craig Blumgart, \& Tran, 2009; Frattali, 1998; Klompas \& Ross, 2004; Yaruss \& Quesal, 2006). Specifically, previous researchers suggest that adults with an increased severity of stuttering may have a higher risk of poor emotional functioning (Craig et al., 2009). Children and adolescents have reported instances of school yard bullying and teasing; such experiences may negatively affect the person's full participation in future vocation and recreational opportunities (Blood \& Blood, 2004; Davis, Howell, \& Cook, 2002; Langevin, 1997, 2000; Langevin, Bortnick, Hammer, \& Wiebe, 1998; Murphy \& Quesal, 2002; Murphy, Yaruss, \& Quesal, 2007a, 2007b; Yaruss, Murphy, Quesal, \& Reardon, 2004). Therefore, tools to assess the experiences facing young people living with a stutter warrant increased prominence and exploration.

Given the myriad ways in which stuttering may affect children and adolescents, there is a need for better information regarding the adverse impact of the disorder for young people. This is particularly true given the fact that even children and adolescents who do not stutter are likely to experience personal and environmental reactions to their developing speaking abilities. These ages represent times of change in young people's lives, and it is not necessarily clear which aspects of the experience of stuttering are unique to stuttering and which are part of growing up and learning to communicate with others. Accordingly, comparison of the 
experiences of children and adolescents who stutter with the experiences of their fluent peers may highlight specific social, emotional, and mental health concerns for this population of young people coping with communication difficulties.

\section{Aims of Study}

The aims of this study were to identify: (a) the reactions of children who stutter (CWS) and adolescents who stutter (AWS) compared to their fluent peers as measured by scores on the OASES questionnaire (Yaruss \& Quesal, 2006, 2010) and (b) the relationship between adverse impact and stuttered speech frequency as measured by percent syllables stuttered (\%SS).

\section{Methods}

\section{Participants}

The group of children and adolescents who stuttered consisted of 95 young people, 50 children $(M=9.64$ years; $S D=1.03$ years; range $=8-11$ years $)$ and 45 adolescents $(M=13.69$ years; $S D=1.55$ years; range $=12-17$ years). They consisted of 75 males and 20 females. All participants were on the waiting list for treatment at a metropolitan university stuttering clinic. The clinic provides specialized stuttering treatment expertise and is respected as a second opinion clinic for previously unsuccessful treatments. All the participants attended primary or secondary suburban or rural schools. Eighty-five participants resided in the metropolitan area and the remaining 10 lived in rural areas ranging from 200 kilometers southwest to 1,600 kilometers northeast of the clinic. Clinicians in the specialist university stuttering treatment clinic assessed all of the participants. Parents and caregivers of the participants who stuttered reported that their children started stuttering during early childhood between the ages of 2.5 and 4 years. Onset of stuttering by parental and caregiver report was described in a manner consistent with developmental stuttering. All participants had previously attended other speech-language pathology clinics for treatment of their stuttering difficulties. None of the participants had received any stuttering treatment in the 3 months prior to the start of this study.

The group of children and adolescents who do not stutter consisted of 95 young people, 50 children $(M=9.66$ years; $S D=1$ year; range $=8-11$ years $)$ and 45 adolescents $(M=13.71$ years; $S D=1.55$ years; range $=12-17$ years). They were recruited and age- and sex-matched as a cohort to the individuals in the stuttering subject group. Researchers obtained parental and caregiver reports for each control participant with no difficulties identified with reading, fluency, or other aspects of speech, language, or communication in the participant's developmental history. In addition, there were no reports of any familial history of stuttering.

\section{Measures}

Researchers determined stuttered speech frequency by rating a representative natural conversational speech sample for each of the 95 participants who stuttered. They obtained a sample of a minimum of 2,000 syllables of conversational speech for each person and elicited when the young person engaged in a conversation with the first author regarding school, family, recreational activities, hobbies, and weekend activities. In the elicitation approach, the author used open-ended prompts that yielded short narratives. The speech samples then were rated by two speech-language pathologists with at least 10 years of experience in the assessment and management of childhood stuttering. Researchers used the Stuttering Measurement System computer program (Ingham, Bakker, Ingham, Moglia, \& Kilgo, 2005) to obtain the percentage of syllables stuttered (\%SS). Interrater reliability was calculated with a correlation coefficient of .91 obtained using a one-way independent group random effect model of analyses (Howell, 2007). This indicates that judgments were both satisfactorily correlated and in agreement. Researchers calculated intrarater reliability using the same method and obtained an intraclass correlation coefficient of .89, demonstrating satisfactory correlation and agreement. 
Researchers used the Overall Assessment of the Speaker's Experience of Stuttering (OASES; Yaruss \& Quesal, 2006, 2010) measurement instrument to assess the adverse impact or negative consequences associated with stuttering. These consequences were described in terms of the speaker's general perceptions of the stuttering impairment; the speaker's affective, behavioral, and cognitive reactions to stuttering; the impact of stuttering on a speaker's functional communication in daily situations; and the impact of stuttering on the speaker's overall quality of life. The adult version of the OASES has demonstrated strong reliability and validity, with Pearson product moment correlation coefficients for impact scores reported to range from .90 to .97 and concurrent validity correlation coefficients ranging from .68 to .83 (Yaruss \& Quesal, 2006).

Researchers administered a modified version of the original OASES that has been adapted for use with children and adolescents who stutter. The child and adolescent questionnaires used in this study (OASES-C) differed from the published adult version (Yaruss $\&$ Quesal, 2010) in that more simple wording was used on certain items. (Note: This study was conducted before the published version of the OASES-S for school-age children and OASES-T for teenagers was available. The adaptations were very similar to the published OASES -S and -T versions and were developed with input and consent from the original authors of the OASES). The OASES-C instruments consisted of 100 items, each scored on a Likert scale ranging from 1 to 5, with higher scores indicating greater negative impact of stuttering.

As in the original published OASES instruments, the adapted questionnaires were divided into 4 sections. Section I (General Information) contained 20 items pertaining to the speakers' perceived fluency and speech naturalness, knowledge about stuttering and stuttering treatment, and overall perceptions about stuttering. Section II (Reactions) contained 30 items examining the speakers' affective, behavioral, and cognitive reactions to stuttering. Section III (Communication in Daily Situations) contained 25 items assessing the degree of difficulty speakers have when communicating in general situations, at school, in social situations, and at home. Section IV (Quality of Life) contained 25 items assessing how much stuttering interferes with the speakers' satisfaction with their ability to communicate, their interpersonal relationships, their ability to participate actively in life, and their overall sense of well-being. These modified OASES tools took each participant 20 minutes on average to complete.

For participants who did not stutter, researchers administered an adapted version of the OASES-C questionnaire scale (OASES-NC) that has previously been used to successfully compare results with fluent speakers (Mulcahy, Hennessey, Beilby, \& Byrnes, 2008). In this adaptation, the word stuttering is replaced with the phrase speaking ability to assess the general impact of speaking on the person's life (Tellis et al., 2000). Researchers converted raw scores for all participants to impact scores using the procedure outlined by Yaruss and Quesal (2010).

\section{Procedures}

Researchers obtained ethical approval for this study through the requisite Human Research Ethics Committee. They obtained informed consent from all participants and their parents or caregivers. Initially, researchers contacted the parents or caregivers of the children and adolescents and provided them with information sheets and informed consent ethics forms. Parents discussed participation with their son or daughter, who confirmed their willingness to participate further in the research. Researchers assessed participants individually in a quiet room within the university clinic. They used an initial 10-minute screening conversation to assess the absence of stuttering in the fluent control participants. They obtained a 30-minute recorded conversation sample based on a series of open-ended questions designed to elicit dialogue and establish rapport for all participants who stuttered. All participants completed the appropriate version of the OASES-C or OASES-NC questionnaire. 


\section{Results}

\section{Between-Group Comparisons}

Descriptive statistics, computed for the \%SS, OASES, and Age, are shown in Tables 1 and 2. Researchers scanned the data for any univariate outliers, calculating mahalanobis distances to identify multivariate outliers. There were no significant outliers. Researchers calculated effect size using Cohen's d (Cohen, 1988). Researchers used an alpha level of .01 (two-tailed) for all statistical tests based on a Bonferroni alpha correction, which was implemented to control for the increased risk of Type I errors when conducting multiple comparisons.

Table 1: Means and Standard Deviations for Children Who Stutter (CWS) and Children Who Do Not Stutter (CWNS)

\begin{tabular}{|c|c|c|c|c|c|c|c|}
\hline \multirow[t]{2}{*}{ Measures } & \multicolumn{2}{|c|}{$\begin{array}{l}\text { CWS } \\
(N=50)\end{array}$} & \multicolumn{2}{|c|}{$\begin{array}{l}\text { CWNS } \\
(N=50)\end{array}$} & \multirow[t]{2}{*}{$t t$} & \multirow[t]{2}{*}{$p$} & \multirow[t]{2}{*}{$d$} \\
\hline & $M$ & SD & $M$ & SD & & & \\
\hline$\%$ SS & 5.71 & 4.03 & - & - & - & - & - \\
\hline OASES - SI & 2.92 & 0.40 & 2.29 & 0.42 & 7.68 & $<.001$ & 1.54 \\
\hline OASES - SII & 3.04 & 0.47 & 1.72 & 0.27 & 17.29 & $<.001$ & 3.44 \\
\hline OASES - SIII & 3.25 & 0.53 & 1.44 & 0.32 & 20.58 & $<.001$ & 4.13 \\
\hline OASES - SIV & 2.88 & 0.53 & 1.10 & 0.23 & 21.93 & $<.001$ & 4.36 \\
\hline Age & 9.64 & 1.03 & 9.67 & 1.00 & -0.10 & .91 & .03 \\
\hline
\end{tabular}

Table 2: Means and Standard Deviations for Adolescents Who Stutter (AWS) and Adolescents Who Do Not Stutter (AWNS

\begin{tabular}{|c|c|c|c|c|c|c|c|}
\hline \multirow[t]{2}{*}{ Measures } & \multicolumn{2}{|c|}{$\begin{array}{l}\text { AWS } \\
(N=45)\end{array}$} & \multicolumn{2}{|c|}{$\begin{array}{l}\text { AWNS } \\
(N=45)\end{array}$} & \multirow[t]{2}{*}{$t$} & \multirow[t]{2}{*}{$p$} & \multirow[t]{2}{*}{$d$} \\
\hline & $M$ & $\mathbf{S D}$ & $M$ & $\mathbf{S D}$ & & & \\
\hline$\%$ SS & 6.41 & 3.90 & - & - & - & - & - \\
\hline OASES - SI & 3.08 & 0.44 & 2.10 & 0.41 & 10.98 & $<.001$ & 2.30 \\
\hline OASES - SII & 3.24 & 0.36 & 1.64 & 0.22 & 25.47 & $<.001$ & 5.36 \\
\hline OASES - SIII & 3.30 & 0.43 & 1.50 & 0.29 & 23.20 & $<.001$ & 4.91 \\
\hline OASES - SIV & 2.97 & 0.48 & 1.08 & 0.22 & 24.02 & $<.001$ & 5.06 \\
\hline Age & 13.69 & 1.55 & 13.71 & 1.55 & -0.07 & .82 & .03 \\
\hline
\end{tabular}

An independent samples $t$-test showed no significant difference between the ages of CWS and CWNS (Table 1).

The majority (62\%) of CWS demonstrated stuttered speech frequency levels between 2 and $5 \% \mathrm{SS}$, with the remaining (38\%) demonstrating greater than $5 \%$ SS (Figure 1). 
Figure 1: Group Mean \pm SD of \% Syllables Stuttered for Children Who Stutter (CWS) and Adolescents Who Stutter (AWS).

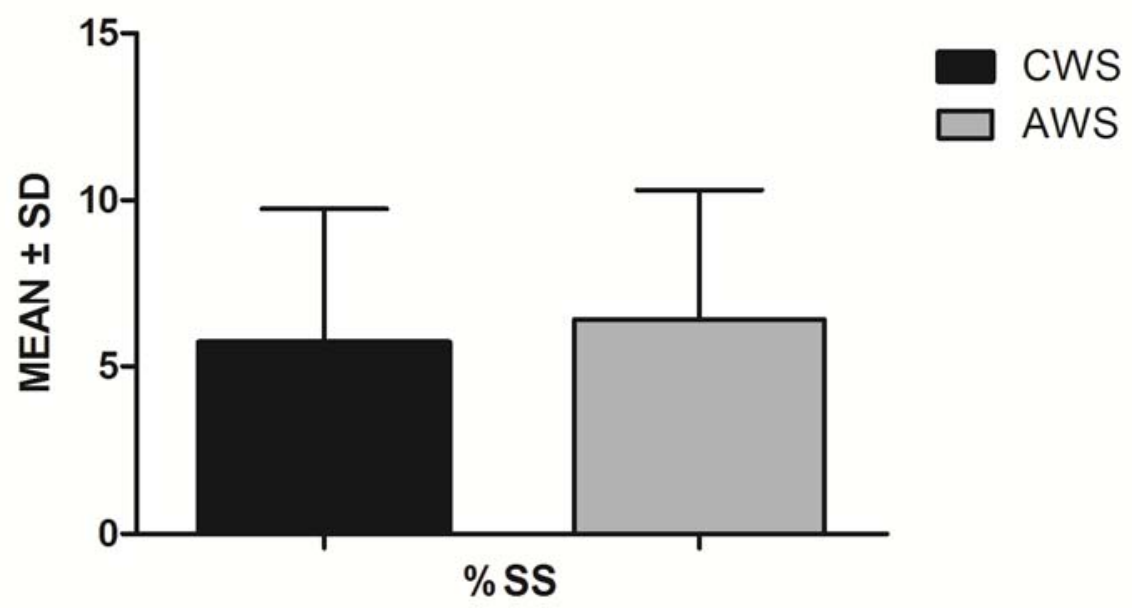

Researchers computed independent samples $t$-tests to test for significant differences between the CWS and the CWNS on the OASES subsection scores. Results (Table 1) demonstrated significant differences between the groups on all measures with large effect sizes (Howell, 2007). All four comparisons of the OASES subscales revealed significant differences between children who stuttered and children who did not stutter (Figure 2).

Figure 2: Group Mean \pm SD of OASES Subsection Items Completed By Children Who Stutter (CWS) and Children Who Do Not Stutter (CWNS).

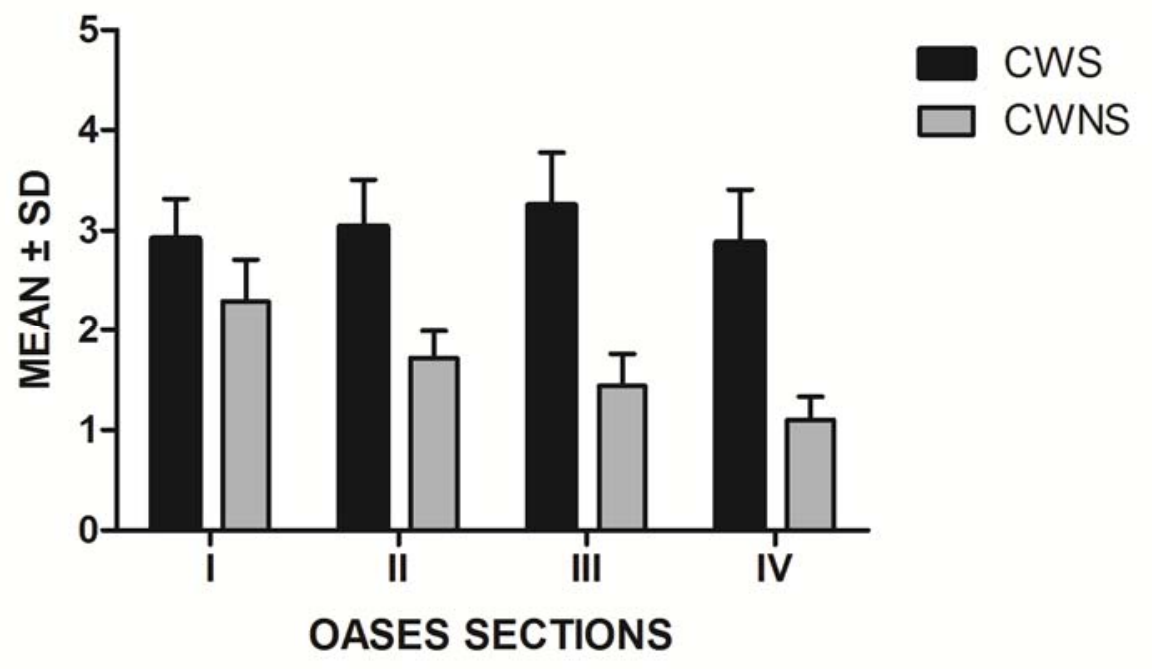

An independent samples $t$-test showed no significant difference between the ages of AWS and AWNS (Table 2).

A majority of AWS (53\%) demonstrated stuttered speech frequency levels between 2 and $5 \%$ SS with the remainder (47\%) demonstrating in excess of $5 \%$ SS (Figure 1 ).

Researchers computed independent samples $t$-tests to test for significant differences between the group of AWS and the fluent AWNS group on the OASES subsection scores. 
Results (Table 2) demonstrated significant differences between the groups on all measures with large effect sizes (Howell, 2007). All four comparisons of the OASES subscales revealed significant differences between adolescents who stuttered and adolescents who did not stutter (Figure 3).

Figure 3: Group Mean \pm SD of OASES Subsection Items Completed by Adolescents Who Stutter (AWS) and Adolescents Who Do Not Stutter (AWNS)

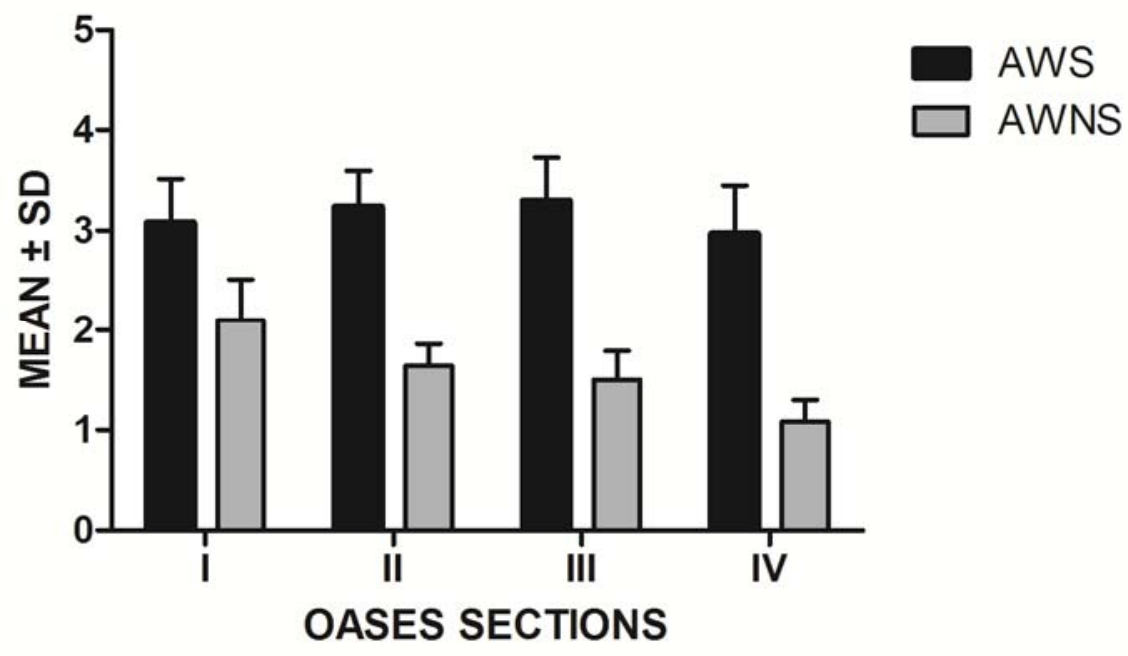

\section{Correlations Between Variables}

Researchers computed Pearson product-moment correlations to determine the interrelationship between each measure within each group.

For the group of CWS, stuttered speech frequency (\%SS) was significantly associated with each of the OASES subscales (Table 3). In addition, children who stuttered demonstrated significant associations between each of the subsections of the OASES questionnaire.

Table 3. Intercorrelations for $C W S(N=50)$

\begin{tabular}{|c|c|c|c|c|c|}
\hline Measures & \%SS & OASES - SI & OASES - SII & OASES - SIII & OASES - SIV \\
\hline \%SS & - & $.53^{*}$ & $.48^{*}$ & $.50^{*}$ & $.42^{*}$ \\
\hline OASES-SI & & - & $.68^{*}$ & $.70^{*}$ & $.48^{*}$ \\
\hline OASES - SII & & & - & $.76^{*}$ & $.82^{*}$ \\
\hline OASES - SIII & & & & - & $.82^{*}$ \\
\hline OASES - SIV & & & & & - \\
\hline
\end{tabular}

Note. ${ }^{*} p<.01$

For the group of AWS, stuttered speech frequency (\%SS) was significantly associated with the OASES-I subscale (Table 4). Moderate correlations between \%SS and other sections of the OASES did not reach significance following the application of the Bonferroni correction. 
In addition, AWS demonstrated statistically significantly associations between each of the subscales of the OASES questionnaire.

Table 4: Intercorrelations for AWS $(N=45)$

\begin{tabular}{|c|c|c|c|c|c|}
\hline Measures & $\%$ SS & OASES - SI & OASES - SII & OASES - SIII & OASES - SIV \\
\hline$\%$ SS & - & $.43^{*}$ & .32 & .34 & .32 \\
\hline OASES-SI & & - & $.51^{*}$ & $.76^{*}$ & $.47^{*}$ \\
\hline OASES - SII & & & - & $.76^{*}$ & $.87^{*}$ \\
\hline OASES - SIII & & & & - & $.76^{*}$ \\
\hline OASES - SIV & & & & & - \\
\hline
\end{tabular}

Note. ${ }^{*} p<.01$

\section{Discussion}

A principal outcome of this study is the finding that children and adolescents who stuttered experienced greater adverse impact on their lives as a result of their speech than their fluent peers. The young people who stuttered showed greater overall concern about their speaking, magnified affective, behavioral, and cognitive reactions to their speaking ability and significantly compromised communication in daily situations. Further, findings were underpinned by the fact these young people experienced a reduced quality of life compared to their fluent peers in society.

The young people who stuttered reported significantly reduced self-awareness and knowledge of their speaking ability; greater affective, behavioral, and cognitive reactions to their speaking ability; greater impact of the environment on their speaking ability; and poorer quality of life compared to children and adolescents who did not stutter. The pattern of results observed in the present study for participants who stutter supports the utility of using a biopsychosocial model when studying quality of life issues with this population.

Previous research has highlighted the prominence of negative reactions to stuttering in very young children (Ezrati-Vinacour et al., 2001; Vanryckeghem et al., 2005). In addition, parental reports have indicated that children who stutter are aware of their stuttering shortly after its onset (Ambrose \& Yairi, 1994; Packman, Onslow, \& Attanasio, 2003). Such findings underpin the potential that stuttering has to affect social interaction from an early age. Analysis of interactive components of the assessment in this study indicate that children and adolescents who stuttered displayed a significant association between stuttered speech frequency (\%SS) and self-awareness and knowledge of their stuttering experience (OASES-SI). A possible interpretation is that young people who continue to stutter, over time, experience an escalation in negativity regarding their communications skills. Interestingly, however, researchers did not find significant correlations between \%SS and other sections of the OASES among adolescents, thereby highlighting the fact that adverse impact can exist independent from the degree of stuttering that a listener may observe (e.g., Blumgart, Tran, Yaruss, \& Craig, 2012; Koedoot, Versteegh, \& Yaruss, 2011; Mulcahy et al., 2008).

In this study, researchers directly compared reactions of children and adolescents who stutter to children and adolescents who do not stutter, the first time researchers have done so. 
The young people in the study who stuttered displayed significantly higher affective, behavioral, and cognitive reactions to their stuttering/speaking ability (OASES-SII) than their fluent counterparts. A small but expected finding was that fluent participants did not show a complete absence of response in terms of their speaking abilities. By comparison, however, the experimental groups of children and adolescents showed significantly much higher affective, behavioral, and cognitive reactions. This has important clinical implications for realistic goalsetting that does not strive for an absence of negative reactions overall.

In this study, children who stuttered demonstrated a significant, positive correlation between \%SS and reactions to stuttering, self-awareness of stuttering, difficulties in daily communication, and quality of life. The children appeared to have developed negative affective, behavioral, and cognitive reactions to their stuttering in comparison to their fluent peers. Such a relationship between stuttered speech and negative reactions supports previous literature (Cooper, 1993; DeNil \& Brutten, 1990; Guitar, 2006; Logan \& Yaruss, 1999; Manning, 2010; Shapiro, 1999; Sheehan, 1970; Vanryckeghem \& Brutten, 1996, 1997; Watson, 1988; Yaruss, 1998; Yaruss \& Quesal, 2004, 2006).

Researchers have determined that quality of life is a potentially important measure when assessing the impact of stuttering (Craig et al., 2009; Klompas \& Ross, 2004; Yaruss \& Quesal, 2006). To date, there is limited literature assessing the impact of stuttering on quality of life in children and adolescents (Mulcahy et al., 2008). A noteworthy finding from this study is the fact that children and adolescents who stuttered displayed significantly lower quality of life responses than did their fluent peers.

In addition, previous researchers investigating quality of life impact suggest that adults with an increased severity of stuttering may have a higher risk of poor emotional functioning (Craig et al., 2009). Such findings have important therapeutic implications for the treatment of children who stutter. The assumption is that the negative impact of stuttering on quality of life is a consequence of chronic stuttering over time (Bloodstein $\&$ Bernstein Ratner, 2008). It is therefore imperative that treatments for children and adolescents improve so that fewer children and adolescents grow into adults who remain stuttering at elevated or severe levels (Craig et al., 2009).

Researchers discovered an important clinical implication from the research, that young people who were fluent also had some degree of negative reaction to their speaking ability. Thus, the goals of treatment addressing negative reactions to stuttering do not necessarily need to seek an outcome of "zero negative reactions" in order to be successful. Helping a child achieve "normal" reactions (which may include some low level of concern about speaking) may be a reasonable outcome, provided those reactions do not interfere with communication.

It also possible for some people who stutter, as a result of treatment, to have scores on measures of communication and psychosocial functioning that are better or more desirable that typically fluent speakers (Manning, 2010).

\section{Limitations and Future Research}

This research used self-report measures to assess the adverse impact of stuttered speech in young people. This form of quantitative measurement presents a number of issues, including the operation of response bias and shared variance between the measures. However, self-report methods are currently one of few available methodologies for the collection of the speaker's attitudes and emotions about their communication. Further, the use of questionnaire methodology is widely accepted as valid and reliable methodology (Turk \& Melzack, 1992). Subsequent research might consider qualitative research methods to verify and cross-validate the self-report responses of such children and adolescents who stutter.

This study constitutes a cross-sectional analysis and the findings have elucidated the adverse impact and negative consequences associated with living with a stutter from a young person's perspective. A recommended longitudinal study evaluating the impact of stuttering in children and adolescents could highlight factors that evolve as prognostic indicators in the 
long-term adjustment to and acceptance of stuttering. In addition, it would be worthwhile to pursue any potential differences between male and female participants in future studies.

We hope that future studies will investigate further empirical support for a biopsychosocial model for stuttering in children and adolescents. It follows that such studies may well elucidate strategies for managing the psychosocial impact of stuttering in a holistic approach to the assessment and treatment of young people who stutter.

\section{Acknowledgements}

This study was supported by Project Grants from the Neurotrauma Research Program (Government of Western Australia). The authors would like to thank all the participants involved and the anonymous reviewers for their helpful comments in improving this manuscript.

\section{References}

Ambrose, N. G., \& Yairi, E. (1994). The development of awareness of stuttering in preschool children. Journal of Fluency Disorders, 19, 229-245.

Blood, G. W., \& Blood, I. M. (2004). Bullying in adolescents who stutter: Communicative competence and self-esteem. Contemporary Issues in Communication Science and Disorders, 31, 69-79.

Bloodstein, O. (1960). The development of stuttering: I. Changes in nine basic features. Journal of Speech and Hearing Disorders, 25, 219-237.

Bloodstein, O., \& Bernstein Ratner, N. (2008). A handbook of stuttering (6th ed.). New York, NY: Thomson Delmar Learning.

Blumgart, E., Tran, Y., Yaruss, J. S., \& Craig, A. (2012). Australian normative data for the Overall Assessment of the Speaker's Experience of Stuttering. Journal of Fluency Disorders, 37, 83-90.

Cohen, J. (1988). Statistical power analysis for the behavioural sciences (2nd ed.). Hillsdale, NJ: Lawrence Erlbaum Associates.

Cooper, E. B. (1993). Chronic perseverative stuttering syndrome: A harmful or helpful construct? American Journal of Speech-Language Pathology, 2, 11-15.

Cooper, E., \& Cooper, C. (1996). Clinician attitudes towards stuttering: Two decades of change. Journal of Fluency Disorders, 21, 119-135.

Corcoran, J.A., \& Stewart, M. (1998). Stories of stuttering: A qualitative analysis of interview narratives. Journal of Fluency Disorders, 23, 247-264.

Craig, A., Blumgart, E., \& Tran, Y. (2009). The impact of stuttering on the quality of life in adults who stutter. Journal of Fluency Disorders, 34, 61-71.

Daley, J. A., McCroskey, J. A., Ayres, J., Hopf, T., \& Ayres, D. M. (1997). Avoiding communication: Shyness, reticence and communication apprehension (2nd ed.). Cresskill, NJ: Hampton Press.

Davis, S., Howell, P., \& Cook, F. (2002). Sociodynamic relationships between children who stutter and their non-stuttering classmates. Journal of Child Psychology and Psychiatry and Allied Disciplines, 69, $141-158$.

De Nil, L. F., \& Brutten, G. (1990). Speech-associated attitudes, stuttering, voice disordered, articulation disordered, and normal speaking children. Journal of Fluency Disorders, 15, 127-134.

De Nil, L. F., \& Brutten, G. (1991). Speech-associated attitudes of stuttering and non-stuttering children. Journal of Speech and Hearing Research, 34, 60-66.

Ezrati-Vinacour, R., Platzky, R., \& Yairi, E. (2001). The young child's awareness of stuttering-like disfluency. Journal of Speech-Language-Hearing Research, 44, 368-380.

Frattali, C. (1998). Measuring modality-specific behaviours, functional abilities, and quality of life. In C. Frattali (Ed.), Outcome measurement in speech-language pathology (pp. 55-88). New York, NY: Thieme Medical Publishers. 
Gabel, R. (2006). Effects of stuttered speech frequency and therapy involvement on attitudes towards people who stutter. Journal of Fluency Disorders, 31, 216-227.

Guitar, B. (2006). Stuttering: An integrated approach to its nature and treatment (3rd ed.). Baltimore, MD: Lippincott Williams \& Wilkins.

Healey, E. C., \& Scott, L. A. (1995). Strategies for treating elementary school-age children who stutter: An integrative approach. Language, Speech, and Hearing Services in Schools, 26, 151-161.

Howell, D. (2007). Statistical methods for psychology (6th ed.). Belmont, CA: Thomson/Wadsworth.

Ingham, R., Bakker, K., Ingham, J., Moglia, R., \& Kilgo, M. (2005). Stuttering Measurement System (version 1.2.0) [Computer software]. Santa Barbara, CA: University of California.

Johnson, W. (1961). Stuttering and what you can do about it. Danville, IL: Interstate Printers and Publishers.

Klompas, M., \& Ross, E. (2004). Life experiences of people who stutter, and the perceived impact of stuttering on quality of life: Personal accounts of South African individuals. Journal of Fluency Disorders, 29, 275-305.

Koedoot, C., Versteegh, M., \& Yaruss, J. S. (2011). Psychometric evaluation of the Dutch translation of the overall assessment of the speaker's experience of stuttering for adults (OASES-A-D). Journal of Fluency Disorders, 36, 222-230.

Langevin, M. (1997). Peer teasing project. In E. Healey, \& H. F. M. Peters (Eds.), Second world congress on fluency disorders: Proceedings (pp. 169-171). Nijmegen, The Netherlands: Nijmegen University Press.

Langevin, M. (2000). Teasing and bullying: Unacceptable behaviour. The TAB Program. Edmonton, Alberta, Canada: Institute for Stuttering Treatment and Research.

Langevin, M., Bortnick, K., Hammer, T., \& Wiebe, E. (1998). Teasing/bullying experienced by children who stutter: Toward development of a questionnaire. Contemporary Issues in Communication Science and Disorders, 25, 12-24.

Logan, K. J., \& Yaruss, J. S. (1999). Helping parents address attitudinal and emotional factors with young children who stutter. Contemporary Issues in Communication Science and Disorders, 26, 69-81.

Manning, W. H. (2010). Clinical decision making in fluency disorders. (3rd ed.). Clifton Park, NY: Delmar, Cengage Learning.

Mulcahy, K., Hennessey, N., Beilby, J., \& Byrnes, M. (2008). Social anxiety and the severity and topography of stuttering in adolescents. Journal of Fluency Disorders, 33, 306-319.

Murphy, B., Quesal, R. W., \& Gulker, H. (2007). Covert stuttering. Perspectives in Fluency and Fluency Disorders, 17, 4-9.

Murphy, W. P., \& Quesal, R. W. (2002). Strategies for addressing bullying with the school-age child who stutters. Seminars in Speech and Language, 23, 205-211.

Murphy, W. P., Yaruss, J. S., \& Quesal, R. W. (2007a). Enhancing treatment for school-age children who stutter. I: Reducing negative reactions through desensitization and cognitive restructuring. Journal of Fluency Disorders, 32, 121-138.

Murphy, W. P., Yaruss, J. S., \& Quesal, R. W. (2007b). Enhancing treatment for school-age children who stutter. II: Reducing bullying through role-playing and self-disclosure. Journal of Fluency Disorders, 32 , 139-162.

Ornstein, A. F., \& Manning, W. H. (2002). Self-efficacy scaling by adult stutterers. Journal of Communication Disorders, 18, 313-320.

Packman, A., Onslow, M., \& Attanasio, J. (2003). The timing of early intervention in the Lidcombe Program. In M. Onslow, A. Packman, \& E. Harrison (Eds.), The Lidcombe Program of early stuttering intervention (pp. 41-55). Austin, TX: Pro-Ed.

Plexico, L., Manning, W. H., \& DiLollo, A. (2005). A phenomenological understanding of successful management. Journal of Fluency Disorders, 30, 1-22.

Plexico, L. W., Manning, W. H., \& Levitt, H. (2009). Coping responses by adults who stutter: Part I. Protecting the self and others. Journal of Fluency Disorders, 34, 87-107.

Quesal, R. W. (1989). Stuttering research: Have we forgotten the stutterer? Journal of Fluency Disorders, $14,153-164$. 
Ramig, P. R., \& Bennett, E. M. (1995). Working with 7-12 year old children who stutter: Ideas for intervention in the public schools. Language, Speech, and Hearing Services in Schools, 26, 138-150.

Ramig, P. R., \& Dodge, D. M. (2005). The child and adolescent stuttering treatment and activity resource guide. Clifton Park, NY: Thompson Delmar Learning.

Reeves, N., \& Yaruss, J.S. (2012). School-age stuttering therapy: A practical guide. Manuscript in preparation, McKinney, TX: Stuttering Therapy Resources, Inc.

Rustin, L., Cook, F., \& Spence, R. (1995). The management of stuttering in adolescence: A communication skills approach. London, England: Whurr Publishers.

Shapiro, D. A. (1999). Stuttering intervention: A collaborative journey to fluency freedom. Austin, TX: ProEd.

Shapiro, D.A. (2011). Stuttering intervention: A collaborative journey to fluency freedom (2nd ed.). Austin, TX: Pro-Ed.

Sheehan, J.G. (1970). Stuttering: Research and therapy. New York, NY: Harper \& Row.

Starkweather, C. W., \& Given-Ackerman, J. (1997). Stuttering. Austin, TX: Pro-Ed

Tellis, C., Yaruss, J. S., \& Quesal, R. W. (2000). Nonstutterers' communication-related attitudes, functional communication abilities, and quality of life. ASHA Leader, 5(16), 170.

Turk, D. C., \& Melzack, R. (1992). Handbook of pain assessment. New York, NY: Guildford.

Van Riper, C. (1982). The nature of stuttering. Englewood Cliffs, NJ: Prentice-Hall.

Vanryckeghem, M. (1995). The communication attitude test: A concordancy investigation of stuttering and nonstuttering children and their parents. Journal of Fluency Disorders, 20, 191-203.

Vanryckeghem, M., \& Brutten, G. J. (1996). The relationship between communication attitude and fluency failure of stuttering and nonstuttering children. Journal of Fluency Disorders, 21, $109-118$.

Vanryckeghem, M., \& Brutten, G. J. (1997). The speech-associated attitude of children who do and do not stutter and the differential effect of age. American Journal of Speech-Language Pathology, 6, 67-73.

Vanryckeghem, M., Brutten, G. J., \& Hernandez, L. M. (2005). A comparative investigation of the speechassociated attitude of preschool and kindergarten children who do and do not stutter. Journal of Fluency Disorders, 30, 307-318.

Watson, J. B. (1988). A comparison of stutterers' and nonstutterers' affective, cognitive, and behavioural self-reports. Journal of Speech and Hearing Research, 31, 377-385.

Wingate, M. (2002). Foundations of stuttering. San Diego, CA: Academic Press.

World Health Organization. (2001). The international classification of functioning, disability and health. Geneva, Switzerland: World Health Organization.

Yaruss, J. S. (1998). Describing the consequences of disorders: Stuttering and the international classification of impairments, disabilities, and handicaps. Journal of Speech, Language and Hearing Research, 41, 249-257.

Yaruss, J. S., \& Quesal, R. W. (2004). Stuttering and the international classification of functioning, disability, and health (ICF): An update. Journal of Communication Disorders, 37, 35-52.

Yaruss, J. S., \& Quesal, R. W. (2006). Overall assessment of the speaker's experience of stuttering (OASES): Documenting multiple outcomes in stuttering treatment. Journal of Fluency Disorders, 31, 90115.

Yaruss, J. S., \& Quesal, R. W. (2010). OASES: Overall Assessment of the Speaker's Experience of Stuttering. Bloomington, MN: Pearson Assessments.

Yaruss, J. S., Murphy, W. P., Quesal, R. W., \& Reardon, N. A. (2004). Bullying and teasing: Helping children who stutter. New York, NY: National Stuttering Association.

Yaruss, J. S., Pelczarski, K., \& Quesal, R. W. (2010). Comprehensive treatment for school-age children who stutter: Treating the entire disorder. In B. Guitar \& R. McCauley (Eds.), Treatment of stuttering: Established and emerging interventions (pp. 215-244). Baltimore, MD: Lippincott Williams \& Wilkins.

Yaruss, J. S., Quesal, R. W., Reeves, L., Molt, L., Kluetz, B., Caruso, A.J., ... McClure, J. A. (2002). Speech treatment and support group experiences of people who participate in the National Stuttering Association. Journal of Fluency Disorders, 27, 115-135. 